\title{
Voting And Lottery Technologies: A Potential Jackpot? An Economic Analysis
}

Maria Cornachione Kula, (E-mail: mkula@rwu.edu), Roger Williams University

\begin{abstract}
Voting irregularities and recount mechanisms used in Florida during the 2000 U.S. Presidential election have brought calls for re-vamped voting technologies and procedures. Many in both the public and private sectors have focused on the Internet as a possible underlying technology that could provide the ease, accuracy, and reliability a twenty-first century voting system should possess. Apart from the difficulties inherent in building an Internet based system from scratch, this solution ignores existing, proven technology, already in use by a majority of states, which could be adapted to provide a cost effective voting system with many desirable characteristics. The technology: computerized, "on-line" lottery systems. Inherently, these lotteries are transaction processing systems, which is what a voting system, at its base, is. Lottery systems are state based, handle vast quantities of transactions reliably, operate under an extremely high level of scrutiny, and are familiar to millions of Americans. This paper examines a lottery technology based voting system from several perspectives and develops an economic welfare analysis of a lottery technology based voting system.
\end{abstract}

\section{Introduction}

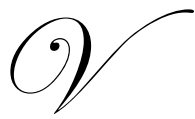

oting irregularities and ballot recount mechanisms (e.g., holding paper ballots up to overhead lights to "discern" voters' intent) used in Florida during the 2000 U.S. Presidential election showcased the inadequacies of antiquated voting systems in use in many U.S. states. The events in Florida and subsequent questions about the legitimacy of the election made the mechanics of states' electoral systems a national public policy issue. Many commentators bemoaned a state of affairs where groceries could be ordered accurately over the Internet, while visual inspection was determining the outcome of a presidential election. Many in both the public and private sectors rushed to conclude that the Internet could be just the right underlying technology for a new, twenty-first century voting system which would address the problems currently in existence. Apart from the difficulties inherent in building an Internet based system from scratch, this solution ignores existing, proven technology which could be adapted to provide a cost effective voting system with many desirable characteristics: "online" lottery systems.

Throughout this paper the term "Internet voting system" is used to denote any proposed voting system that relies on the public Internet; that is, one that relies on a collection of publicly accessible networks (routers, trunks, modems) coupled together, over which voting application software would be run (e.g., when an individual accesses eBay, this access occurs over the public Internet). A "lottery based" voting system refers to a proposed system based on the technology that computerized lotteries in the U.S. currently use to accept, record and validate lottery wagers: that of specific application software running over private networks substantially under the physical control of the lottery operator (i.e., an individual cannot access a lottery system unless placing a wager).

This paper considers the efficacy and implications of lottery technology based electoral systems. The paper is organized as follows: section 2 discusses the critical elements necessary for a sound voting system; section 3 presents the problems inherent in any scheme relying on the Internet as an underlying technology; section 4 details

Readers with comments or questions are encouraged to contact the author via email. 
how a voting system based on currently used lottery technology meets the requirements needed for sound elections; section 5 frames the discussion in terms of an economic welfare analysis, and section 6 concludes.

\section{Characteristics of a Sound Voting System}

It is widely acknowledged that in order for an electoral system in a representative democracy to maintain its integrity, it must ensure three things: the anonymity of the voter, the security of the vote, and universal access to the polls (privacy, security, and equality).

The systems currently in use in many states (e.g., paper ballots, lever machines) result in clear violations of the security principle. A study by the California Institute of Technology and the Massachusetts Institute of Technology (CalTech-MIT, 2001) found that between four and six million presidential votes were lost due to the election process in 2000. It also estimated that one and a half million presidential votes were not recorded in 2000 due to difficulties users had with voting equipment (CalTech-MIT, 2001). Questions have also been raised as to whether universal access to the polls was upheld during the 2000 presidential election, as complaints were heard regarding polling place access denials to Blacks in Florida.

Another important principle in the U.S. is that of federalism. Historically in the US, elections, whether for animal control officer or president, are local matters. States (via counties and municipalities) fund elections and set state election laws. While the federal government does have recommendations regarding voting machines' reliability and "friendliness," currently the federal government does not provide funds to states for running elections. An important feature of any proposed enhancement to the electoral system would be the preservation of state control of elections.

Beyond problems due to outdated voting systems, another widely acknowledged problem with current voting schemes is the prevalence of fraudulent votes. Not surprisingly, absentee ballot fraud currently is the most common type of vote fraud. Voting which occurs in a polling place and requires the physical presence of the voter allows election officials to verify the identity of the voter. Any voting done remotely (e.g., via mail) removes this layer of identity checking. Idealized versions of the perfect voting system envision voters using the Internet to cast votes from home PCs. To simplify, this paper assumes that both Internet and lottery based voting systems would be implemented in centralized polling places where voters would present themselves to election authorities.

\section{Internet Voting}

Advocates of "e-government" and "e-democracy" see the Internet as an enabling technology that can strengthen representative democracy in two major ways: (i) via reform of the process by which government services are delivered and (ii) the manner in which citizens participate in the process of governance, including "e-voting", or Internet voting. Additionally, beyond streamlining or improving the mechanics of the electoral process, many believe that the introduction of new technologies may increase democratic participation. In fact, an Internet based voting system would contain deficiencies that render it inappropriate as a short to medium term solution in electoral technology. Problems exist regarding each of the three principles (security, and privacy, equality) underlying a sound electoral system.

An important concern voiced during the Presidential election was the disparate impact various ballot formats and various types of voting equipment had on minority and low income communities versus wealthier communities. Not only would an Internet based voting system not solve the problem of voting inequality, it would exacerbate it. A study by the National Telecommunications and Information Administration has found evidence supporting the existence of a "digital divide" in the U.S. on both racial and income planes: Whites are more likely to have access to the Internet from home than Blacks and Hispanics have from any location, and urban households with incomes over \$75,000 are over twenty times more likely to have home Internet access than rural households at the lowest income levels (National Telecommunications and Information Administration, 1999). The existence of a "digital divide" implies that some groups are less familiar than others with modern technology and may be less comfortable using these technologies for voting. While this hurdle could be overcome with ongoing exposure, a more 
pernicious effect of a move to "hi-tech" voting systems is possible as poor communities may not be able to bear the cost of centralized, interactive voting systems, burdening them with more error-prone systems.

With an Internet based, distributed interactive voting system (where individuals vote at a polling place and where votes are sent electronically over the Internet to a central repository), serious security concerns exist. Rogue individuals would view election tampering as an irresistible target, and the possibility of e-espionage organized by foreign governments cannot be discounted. Concerns about e-espionage are not illegitimate. A recent Wall Street Journal article reported "...hackers traced back to Russia were found to have been quietly downloading millions of pages of sensitive data, including one colonel's entire e-mail inbox ... During three years, most recently in April, government computer operators have watched - often helplessly - as reams of electronic documents flowed from Defense Department computers, among others...Security testers at the Pentagon's National Security Agency routinely hack into U.S. military networks - and without the Pentagon noticing $99 \%$ of the time..." (Wall Street Journal, June 27, 2001.)

Perhaps the most troublesome aspect of Internet voting would be the inability to determine if tampering had occurred. Hackers could divert users to the wrong web page, resulting in voters interacting with an illegitimate site. Hackers could also hijack a vote in transit, by changing the contents of the vote after the vote has been cast. Under both scenarios, voters believe they have cast their votes correctly. Additionally, hackers could cause major disruptions by "flooding" the Internet with bogus traffic during voting hours, thus overwhelming servers' ability to handle true transactions and slowing or shutting down the polls.

Another issue related to the security of an electoral system is dispute resolution: would Internet voting systems leave an audit trail? In recent elections in Brazil using electronic technology, for example, votes cast in each polling station were added to a running total for each candidate (Financial Times, June 20, 2001) and were not kept in any form for possible later inspection. A system in development for Ireland uses a touch screen for vote casting. Votes are stored on a "ballot module" which is removed from the polling station and brought to a counting center (Irish Times, June 18, 2001). This leaves open the possibility of theft or tampering in transit. A dependable audit trail is a desirable characteristic which next generation voting platforms should provide.

An important factor when considering the move to an Internet voting system is the receptivity of the voters. A Hart-Teeter poll conducted for the Council for Excellence in Government (2000) found that the American populace has significant concerns about the Internet:

- $\quad 66 \%$ are very concerned about hackers breaking into government computers

- $\quad 55 \%$ are very concerned about government employees misusing personal information

- $\quad 53 \%$ are concerned about the potential for less personal privacy.

Regarding Internet voting in general, the survey found that 59\% are opposed to voting over the Internet, with $48 \%$ of this "strongly" opposed (Council for Excellence in Government, 2000). It appears that a voting system based on the Internet would not have voter support, an obvious, necessary element for any new voting scheme.

A final factor affecting adoption is cost. Aside from development and deployment costs, a large portion of the overall cost of an Internet based voting system would be related to testing. Any widespread use of an Internet based voting system for a public election would need rigorous testing, on the order of what occurs with military products, particularly in light of the noted poll results. The testing that would need to occur to allay concern is likely to be prohibitive.

\section{State Lotteries}

Advocates of an Internet based voting system ignore existing, proven technology, already in use by a majority of states, which could be adapted to provide a cost effective voting system with many desirable characteristics. The technology: computerized, "on-line" lottery systems. Inherently, the lottery infrastructures are transaction processing systems, which is what a next generation voting system, at its base, should be. An incremental change 
from the current system would simply have voters go to a polling station equipped with either lottery terminals or similar devices. Voters would mark their "bet-slips" with their choices.

A lottery based voting system would uphold the three principles needed for a legitimate electoral mechanism. Regarding security, lotteries routinely and accurately handle millions of transactions. They are trusted as final verifiers of winners of jackpots as high as hundreds of millions of dollars. Lotteries in the U.S. have incorporated technical redundancies and fault tolerant software and hardware into their designs to guard against service interruption (and typically face severe contractual financial penalties should service be interrupted, even for short periods of time). They are consistently able to guard against fraud. State control and scrutiny of lottery operations keeps it free from corruption. Additionally, just as a lottery terminal "reads" a betslip and alerts users to inadmissible slips, it would be known instantly by the voter and election officials if a vote were tallied.

There is also the possibility of a paper, as well as electronic, audit trail as voters could, if desired, be given a receipt with their vote noted on it. These receipts would be imprinted with a serial number, which would be recorded along with the vote, allowing for later verification that serial number " $x$ " did indeed vote for candidate " $y$ " as recorded electronically. Voter anonymity would be maintained, as the serial number would be generated randomly.

Regarding equality, consistent generalizations regarding the demographics of lottery players show that those groups likely to be the victims of voting inequality with current systems are those most familiar with lotteries: laborers play the lottery more than professionals, lottery play falls with formal education, and Hispanics in the west and Blacks in the east are more likely than Whites to play (Clotfelter and Cook, 1990). As a commodity, the lottery has broad market penetration: about $90 \%$ of the US population lives in states with state lotteries. Thus a voting system based on the lottery would be familiar and easy to use for most citizens. Just as importantly, since lotteries are deployed on a state wide basis, it can be implemented across all jurisdictions, wealthy or poor, within a given state, and its adoption could be made on a state-by-state basis.

Running lotteries is one of the most visible state government activities and if used for voting, could increase voter turnout and restore people's confidence in government (the government as finally "doing something right"). A lottery technology based system has other advantages. It would be possible to have a voting period greater than one day. Notification of the winner could be done almost "instantaneously". Additions to a baseline voting system based on existing lottery technology include the possibility of voting at a corner convenience store. This possibility, as remote Internet voting does, would need to rely on some form of reliable authentication technology such as biometrics (e.g., retina scan) in order for it to be feasible, but would avoid issues of equipment compatibility inherent in schemes with voting over home PC's.

Some critics oppose government sponsored gambling operations and can be expected to forcefully oppose using lottery technology for voting purposes, perhaps suggesting a move to optical scan systems. One difference between a lottery based system and an optical scan voting system is that any system and equipment upgrade would be far less complex, as most states currently have lottery equipment. Additionally, lottery technology has been extensively field tested for years and states with lotteries have the "know how" or operational capacity to deal with lottery technology itself and the lottery suppliers.

\section{Welfare Analysis}

A voting system is a pure public good: it is non-excludable by design; it is non-rival, as one voter's vote does not diminish another's vote (assuming no degradation in security, privacy, or equality as volume increases). A demand curve for a voting system exists, but as with all public goods it is difficult to measure demand accurately. With a private good, agents reveal their preferences by either buying or not buying the good at a given price. This does not occur with a public good. A survey to determine voter preferences would be unreliable. A voter/taxpayer knows that once a sound voting system is in place, he or she cannot be excluded from it. Voters/taxpayers also have no incentive to accurately answer the question: "How much would you pay in taxes for a sound voting system?." Jerry Hausman, an economist at M.I.T., doubts that the value of a public good can be measured accurately: "The only way to do it is to ask people what they would be willing to pay, and in my view you ask people questions like 
that and you get very upwardly biased results. When somebody calls you on the phone to ask, it's not real money." (The New York Times, October 17, 1999).

While it cannot be measured accurately, it is possible to a sketch a demand curve in "price per vote $(\$)$ " and "quantity of votes" space (see Figure 1.). At prices above $\mathrm{p}^{\text {high }}$, demand would be zero. Below some price $\mathrm{p}^{\text {low}}$, quantity of votes demanded would equal the entire voting population. At intermediate prices, the higher the price, the lower the quantity of votes demanded. In other words, there is some range of prices for which it would be acceptable to have less than the total population's votes be valid. This is the situation prior to 2000 , where antiquated voting systems with high error rates existed.

Now consider the supply curve for votes. Each technology (lever, optical scan, Internet, lottery) would have its own supply curve. That is, suppliers employing various technologies would be able to "produce" a given quantity of votes at various prices. The supposition of this paper is that a system based on existing lottery technologies could "produce" more votes at a lower cost than an alternative Internet based system, given the extensive field testing lottery systems have undergone. Additionally, after dealing with lottery systems for many years, most states have an existing capacity to deal with this technology and supplier companies.

The equilibrium quantity of the number of votes and price per vote is determined in the usual way via the intersection of supply and demand. An optimal allocation, or efficient level of output, exists for a voting system, as it does for any public good (Samuelson, 1955). Prior to the election of 2000, an equilibrium price and quantity existed where the optimal quantity was below the population ( $\mathrm{E}^{0}$ in Figure 1.). The difficulties in Florida and attention on error rates of antiquated systems can be represented as a shift to the right in the demand curve from $\mathrm{D}_{0}$ to $\mathrm{D}_{1}$; voters/taxpayers would be willing to pay a higher price to deliver a given quantity of votes. If the whole population is to be "served," a system based on lottery technologies provides this at the lowest price per vote ( $\mathrm{E}^{1}$ in Figure 1.).

\section{Figure 1.}

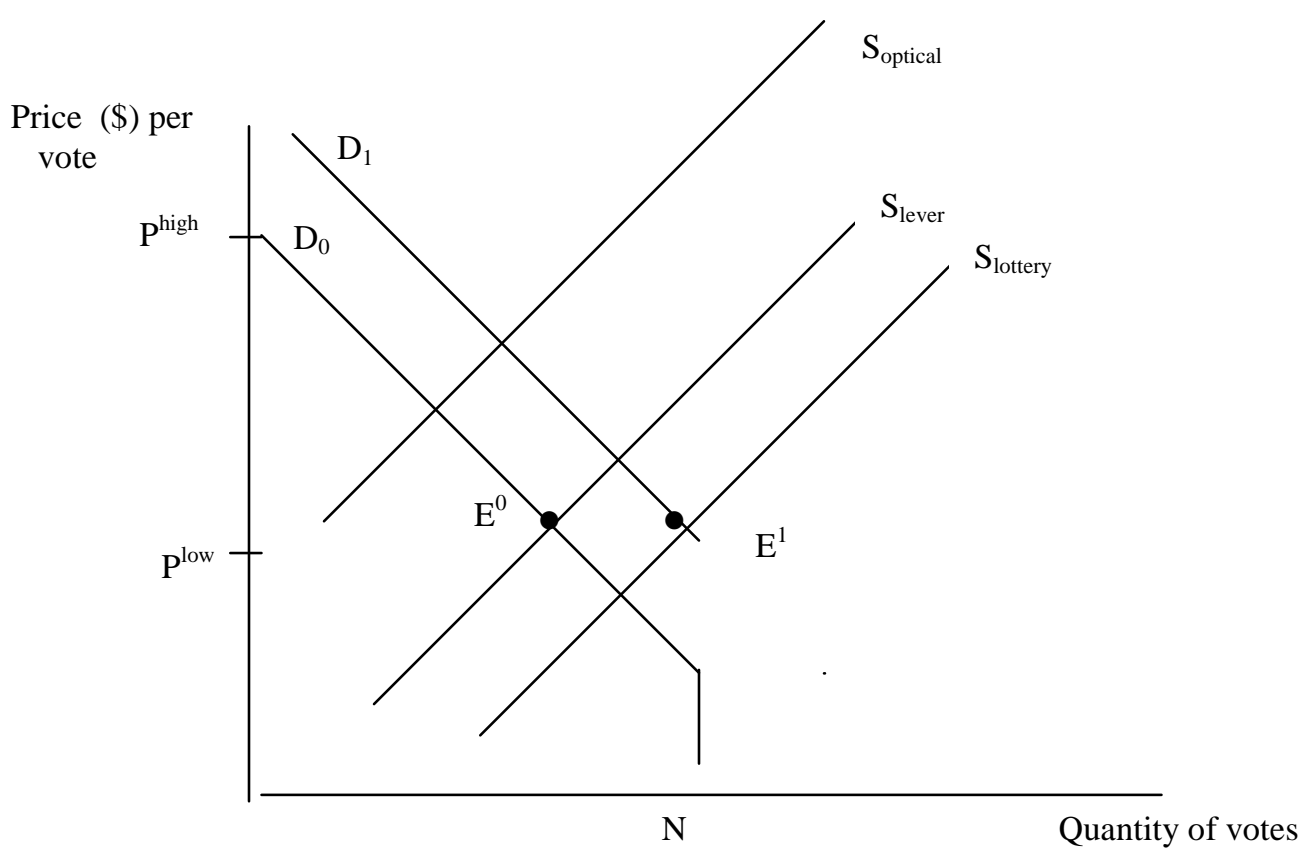

\section{Conclusion}


This paper has provided an initial foray into the question of which type of voting technology states should migrate to. Voting systems based on the public Internet are not feasible in the short to medium term given the inherent security and privacy issues, as well as the expected high costs of testing such a system. A voting system based on current lottery technology offers a better solution, as all criteria necessary for a sound system would be met. It is also possible that using this technology could increase voter turnout, a goal of most electoral public policy initiatives. The logical next step to gauge the possibility of implementation would be to accurately estimate the costs of such a system, measure the level of potential criticism of tying a gaming technology to voting, and, ultimately, determining the level of interest of current lottery technology suppliers.

\section{References}

1. Caltech-MIT Voting Technology Project, 2001. "Voting-What is; What Could Be", July. http://www.vote.caltech.edu/Reports/index.html

2. Clotfelter, C., and P. Cook. 1990. "On the Economics of State Lotteries," The Journal of Economic Perspectives, Vol. 4, Issue 4, pp. 105-119.

3. Council for Excellence in Government, 2000. "E-Government: the Next American Revolution," www.excel.gov.org/techcon/egovex/index.htm

4. $\quad$ Financial Times, June 20, 2001. "Florida Fiasco Fuels Pressure for Poll Reform."

5. Irish Times, June 18, 2001. "Comuputimes: More than One Way of Capturing the E-Vote."

6. National Telecommunications and Information Administration, U.S. Department of Commerce, July 9, 1999. "Falling Through the Net: Defining the Digital Divide." http://www.ntia.doc.gov/ntiahome/digitaldivide

7. $\quad$ The New York Times, October 17, 1999. Week in Review, p.5.

8. Samuelson, P. 1955. "Diagrammatic Exposition of a Theory of Public Expenditure," Review of Economics and Statistics, XXXVII.

9. $\quad$ Wall Street Journal, June 27, 2001. "E-Espionage Rekindles Cold-War Tensions.” 